\title{
Video capture of symbolic activity in toddler initiated play
}

\author{
Avis Florence Ridgway
}

\section{Correspondence:}

avis.ridgway@monash.edu.au Monash University, Melbourne, Australia

\section{Springer Open}

\begin{abstract}
This article is backgrounded by researchers using of visual methodology for naturalistic research to document young children's learning. Recent interest in the speed and immediacy of mobile phone video capture leads to new opportunities in educational research. This small study aims to find if mobile phone video is an appropriate research tool for the capture of fleeting moments of learning, in toddler initiated play. Inspired by participation in an ethically approved pilot project: 'Studying Babies and Toddlers: Cultural Worlds and Transitory Relationships', the study uses a cultural-historical Theoretical approach to analyse mobile phone video data of one toddler's pontaneous play activity. It is argued that greater attention be paid by educators to transitory moments of toddler play in relation to their pedagogical significance. A fortuitous moment of toddler initiated symbolic play activity is video captured on mobile phone and used for discussion. Drawing on Vygotsky's concepts of the social genesis of higher mental functions and perezhivanie, the toddler's initiated symbolic play activity is analysed. Analysis is supported by visual methodology, where video image data are linked with transcript to create a narrative of the moment of toddler's initated play. Data are found to exemplify the ontogenesis of higher mental functions being culturally mediated and supported in the toddler's symbolic play activity. Futhermore, findings show how tactile and visual qualities of a cultural object attract a toddler's sensory responses, which in turn, activate the creative moment of symbolic play. The toddler's momentary playful action captured on mobile phone video, sheds light on how symbolic activity reflects thinking processes to offer insight into how toddler (Luci) can, in a passing moment, imbue a cultural object with new symbolic meaning. Findings imply that using mobile phone video for later review, makes it possible for educators to pay more immediate attention to toddler's activity in frequently overlooked transitory moments of play. Potentially, the ubiquitous mobile phone can help educators discover the pedagogical significance of a toddler's smallest moment of symbolic activity, and in practice, offer ethical and caring extension to support their learning.
\end{abstract}

Keywords: Toddler initiation, Symbolic play activity, Cultural-historical approach, Transitory moments, Mobile phone video

\section{Introduction}

The background context to the small study under discussion in this article, includes the researcher's involvement using visual methodology for naturalistic research in combination with a personal fascination for documenting young children's learning. A recent interest in the speed and immediacy of mobile phone video capture has brought new opportunities to early childhood educational research, especially for the recording and sharing of toddler

(c) The Author(s). 2018 Open Access This article is distributed under the terms of the Creative Commons Attribution 4.0 International License (http://creativecommons.org/licenses/by/4.0/), which permits unrestricted use, distribution, and reproduction in any medium, provided you give appropriate credit to the original author(s) and the source, provide a link to the Creative Commons license, and indicate if changes were made. 
activity across family, institutional and community settings. This study aims to find if mobile phone video is an appropriate research tool for capturing in particular, the fleeting spontaneous moments of learning in toddler initiated play. Inspired by participation in an ethically approved pilot project: 'Studying Babies and Toddlers: Cultural Worlds and Transitory Relationships', a cultural-historical theoretical approach is used to analyse mobile phone video data of one toddler's spontaneous everyday play activity. It is argued that if greater attention is paid by educators to what happens in transitory moments of toddler initiated play, its pedagogical significance may inform practice. The research is built around a fortuitous moment of toddler initiated play activity with felt beads on a string, captured on mobile phone video by the researcher. Vygotskian concepts of the social genesis of higher mental functions and perezhivanie are drawn upon and later exemplified. Analysis of a toddler initiated play activity uses visual methodology that involves video image data linked with video transcript to create a research narrative of the toddler's play. The research narrative exemplifies the ontogenesis of higher mental functions being culturally mediated and supported in the play activity, where a perezhivanie becomes evident in the tactile and visual qualities of an external cultural object (a beaded felt necklace). This attracts the toddler's sensory responses, which in turn, internalise, motivate and activate a creative moment of symbolic play. The toddler's playful action is captured on mobile phone video and helps to clarify how symbolic activity relates to the young child's thinking processes. The video data offers insight into how toddler Luci, in a passing moment, imbues a cultural object with new symbolic meaning. This implies that by using mobile phone video, it is possible for family, researchers and educators to pay detailed attention to toddler's thinking in the often unseen and overlooked transitory moments of their playful actions. Potentially, the use of the ubiquitous mobile phone can support discovery of the pedagogical significance in a toddler's smallest moment of play activity. In practice, this may build awareness for those living, playing, and working with toddlers, to ethically and carefully consider ways to extend learning in moments of toddler initiated symbolic activity.

\section{Theoretical background}

In this article, a cultural-historical theoretical approach to analysis of data is informed by Vygotsky's concepts of the social genesis of higher mental functions and perezhivanie.

\section{Cultural historical research}

The notion that a toddler's play activity is configured subjectively in an affective relationship within a particular cultural, social and historical situational context, is widely understood (Elkonin 1978; Bozhovich 2009; Gonzalez-Rey 2009; van Oers 2010; Kravtsov and Kravtsova 2010). In addition, current research shows that participation in symbolic play activity is wholly embedded in a toddler's daily life (Hedegaard 2008; Fleer 2010, 2014; Li et al. 2017). This is consistent with the context of the example to be discussed, where, embedded in a short walk with toddler Luci, symbolic play activity was videoed by researcher on a moblie phone. The transitory moment that was video captured, holds affective actions configured subjectively by toddler Luci. These actions reflect the cultural and historical elements that offer research insight into the broader context of a toddler's symbolic play activity. 


\section{Ethics of historial detail}

Toddlers orient themselves to their immediate world, over the passing rhythm of days and nights. Their immediate world, often contained in a transitory moment, may be overlooked. It is in cultural - historical research, that ethical considerations of historic values, emotions, and familial social settings, are provided in finer detail, in order to acknowledge those influences on learning. Toddlers generally make meaningful personal connections as they become increasingly familiar with the complex reality of what is present, both in and around them. Educators, peers, family, and toddlers' interactive experiences, may also involve strong and diverse feelings connected to their surrounding reality. This can include perceived smells, sounds, sights, spaces, and materials. These richly complex elements present in daily interactions, form the toddler's "phenomena of reality" as noted by Bozhovich (2009, p.2). Such phenomena may be considered fertile ground for growth of a toddler's abstract thinking, because they draw upon the toddler's foundational historical experiences and personal awareness. The growth of symbolic activity in a playful toddler, can therefore be more fully understood, when investigated in the light of its historical development. Historical development is the basis of the research process that gives thought to the reconstruction of a very young child's mental function and how the toddler actually moves towards ... "using a sign as a means for organizing behaviour" (Vygotsky 2004, p.39). As such, an historical study of a toddler's learning does require accounting for the dynamic movement that may be hidden in transitory moments of a toddler's rapid and responsive actions (Vygotsky 1997). Researchers Quinones et al. (2017, p. 176), visually identify and theorise transitory moments in their research data on infants and toddlers as "moments of affective action". In this article, the transitory moments of toddler initiated activity are identified from the toddler's perspective, and understood as being afffective and temporal in nature.

\section{Emotion cognition and environment}

Emotion, cognition and the environment of the young child are unified, according to Vygotsky (1994), in the deeply felt and lived daily experiences. Vygotsky conceptualizes the unification of cognition and environment, in a Russian term 'perezhivanie': "how a child becomes aware of, interprets, and emotionally relates to a certain event" (Vygotsky 1994, p. 340-341). Perezhivanie is not just a cognitive or emotional reaction of the young child; rather it should be thought of differently, as a complex nexus of the young child's various mental functions including their thinking, emotion, memory, will, and capacity for reflection. Perezhivanie may also be understood as a form of active individual refraction of changes, experienced in the young child's particular environment (Veresov 2016; Veresov and Fleer 2016). There is no equivalent English word that covers Vygotsky's original concept, however Quiñones and Fleer (2011) translate perezhivanie as 'vivencias'; a Spanish word that accounts for emotion in the young child's lived experience. The data example used, shows a toddler's spontaneous action that suggests a complex moment of perezhivanie where "affective and volitional tendency stands behind thought" (Vygotsky 1987, p.282). What is clear, is that the toddler's lived experiences, and, in particular, the video captured self initiated playful activity, occur in a holistic learning context. The importance of the holistic nature of a toddler's learning 
context cannot be overlooked. The contextual environment of a toddler "may include human activity related to cultural signs, symbols, language systems, objects, values and rituals" (Ridgway et al. 2015, p.9). Mahn and John-Steiner (2002, p.48) for example, discuss the notion of the environment as "a conscious motivating sphere that includes the child's inclinations and needs, the interests, impulses, affect and emotion" that relate to what is behind the toddler's thought, language and action. They suggest that development of competence and social independence in the toddler, will arise in an environmental context where "human connection and caring support" co-exist (p. 50). This adds to the argument of the importance for educators and researchers alike, to take a more holistic perspective in relation to what happens in a toddler's momentary actions.

\section{Holistic views}

Research into the lives of toddlers is both exciting and complicated. The dynamic and holisitic nature of learning contexts across a toddler's life at home, in the community and within their social situation, is examined in the theoretical work of Fleer and Hedegaard (2010). They argue that "The reconstruction of the child's competences is accompanied by reconstruction of the child's consciousness to reality" (2010, p.151). The toddler's reality in the presented example, reflects Luci's whole social situation. In the toddler's cultural context of home and community practices, symbolic activity (e.g. counting and drawing) is used and valued. An important question for the researcher is how can one know what the toddler's subjective experience is, when a new phenomemon such as necklace of felt beads, is encountered?

In toddler initiated symbolic playful activity, there will not be an artifical or superficial use of an abstraction (such as a sign or word) but rather, according to Gonzalez-Rey (2009), a subjectively configured production. This production will have personal meaning for the toddler that reflects a unity of thoughts and emotions embedded in their daily life. Gonzalez-Rey (2009) expands Vygotsky's thinking by suggesting the researcher considers "Subjectivity as a continuous production of symbolic-emotional configurations...” (p.71).

In addition, Bozhovich (2009) prompts researchers to look closely and think further about the early development of abstract forms of thinking in young children, in order to consider whether or not, the frequently suggested stages of development in age, really exist. Bozhovich (2009, p.2) writes “....the child's mental development has its own internal logic, its own laws, and is not a passive reflection of the reality within which this development takes place". Toddlers are usually active participants in family life. In the example to follow, grandparents take toddler Luci, for a walk in her stroller. Luci engages in a transitory moment of symbolic play activity when playing with her grandmother's felt necklace, according to her own internal logic,. Her response is most typical of cultural behaviour, which Vygotsky (1997, p.60) suggests occurs when "the child solves an inner problem by means of exterior objects". The challenge offered to the toddler in the case example was the handling of an exterior object (the felt necklace). This challenge prompts an original, creative assignation of meaning by the toddler, associated with the process of counting. The felt necklace, as the exterior object, "acquires the functional importance of a sign" (Vygotsky 1997, p.60). 
Exploring the phenomena of creativity and engaging creatively, Wagoner (2017) refers to the young child making spontaneous and novel linkages across "different domains of experiences" (p.25). He invites educators to seek environments that guide and excite the young child's imagination.

Writing about pedagogical play, Ridgway et al. (2015, p.47) note that "When children start to relate to their world, objects and artefacts become familiar as they play with them. The child in play has purposes and intentions, which are intellectual and affective, and develop as their play progresses." The example in this article, shows how an artefact prompted the toddler to initiate counting in a transitory and transformational moment of playful, spontaneous and symbolic activity.

\section{Methodological and ethical considerations}

\section{Visual methodology}

The power of visual methodology is now being more fully realised in research (Fleer and Ridgway. 2014). Tools used for visual methodology in this research included the use of video and screen shot techniques to capture, analyse and conceptualise a moment of toddler play, For the case example, data collection began spontaneously, using a mobile phone to video capture a momentary experience in which toddler, Luci 23 months, and two adults (grandparents) participated.

\section{Ethical considerations}

The ethical considerations for toddler Luci (pseudonym) relate to informed consent of family supported by the fact that she was already an agreed participant as a focus child (one of six) in the ethically approved wider pilot project: Monash University Human Research Ethics Committee (MUHREC) (CF14/2789-2014001523) 'Studying Babies and Toddlers: Cultural Worlds and Transitory Relationships'. Over time, Luci became the subject of further research interest by her family, and in particular her grandmother, who participated in the original pilot project. Parent permission to record and share further exchanges between Long Day Care (LDC) and home was given by Luci's family for research purposes. Permission forms remain securely stored in office files.

Extension of research into Luci's community activity was inclusive of her diverse learning contexts (Vadeboncoeur et al. 2014) and considerate of ethical aspects related to Luci's awareness (or otherwise) of being spontaneously video recorded by mobile phone.

Video and still image technology brought new opportunities for Luci to see herself and also build knowledge of established family cultural activity. Luci's family regularly record and document everyday activities. This regular capture of Luci's shared moments, has over time built collective memory for Luci and provided memory traces for self- identity. When Luci's gestural responses and vocalisations are brought to attention of other family members, through moments of mobile phone capture, her interests become widely acknowledged and supported in family life. Luci's is therefore placed in a child-led situation not a laboratory or experimental one, where she may be imposed upon. There is 'the spirit of the child as a natural guide' (Trevarthen, vi 2017) in her research context. Video on mobile phone is widely used in Luci's family context and in 
her LDC context. Mobile phone technology enables Luci's family to receive frequent snap shot moments of shared activity in her Long Day Care (LDC) setting.

\section{Extending knowledge of community activity}

The research around toddler Luci's wider relationships with her community and family members offered an additional perspective to pilot study data of her participation videoed in LDC. Greater awareness of Luci's movements through the community whilst going to and from the LDC site would add to the research investigation of how learning can occur in the passing moments of embodied learning in a toddler's daily life.

One way to share any discoveries is through video documentation. The use of mobile phone video to capture the immediacy of a transitory moment, requires the researcher to be aware of the toddler's activity and open to filming spontaneously. In the toddler's daily walks to LDC, the recording of the smallest gestures and signals are vital in the sense that they indicate the care for, and ongoing interest in toddler Luci. This attitude of interest and care reflects the ethical approach taken in the research example. The transitory moment, filmed spontaneously on mobile phone and used as data for this article, happened during a daily walk and was not pre-planned. Responsive and attuned to an unplanned opportunity for documenting the toddler's daily life, the researcher realised during the walk that a special moment was unfolding. Familiar with being documented by her family, Luci continued her playful activity uninterrupted during the short mobile phone video capture. The fleeting experience was later shared with Luci and her parents for reflection, discussion and the researcher's analysis. Paying attention to the smallest moments of toddler activity, only becomes possible when video data is available. It stabilises the action, making moments shareable and open to interpretation.

In the spirit of ethics of the wider project, methodology remained consistent for extended data used in the example discussed in this article.

\section{The example}

\section{Context}

The example involves 23 month old toddler Luci and her grandparents. Initially they walk to a local park and then take Luci to visit her long day care centre. When walking with the stroller, Luci indicates an interest in the colourful felt bead necklace that grandmother is wearing. At the park grandmother puts the felt necklace around Luci's neck. Each colourful felt bead appears like a layered lolly individually made and loosely strung on a thick string. The sensory qualities of the necklace capture Luci's attention (Fig. 1). Placing the felt necklace around Luci's neck prompts an exploratory response (Fig. 2) and initiates action (Fig. 3) where Luci moves the felt beads along the string.

\section{Sensory response}

Toddler Luci uses her senses. She looks carefully at the felt necklace that grandmother has lovingly placed around her neck. She looks at and touches the individual felt beads (Fig. 2). Luci discovers that the soft felt beads are movable. Each different bead appears like a colourful lolly. When Luci explores the felt bead necklace (a cultural object), she starts to move the beads along the string on which they are threaded (Fig. 3). The beads 


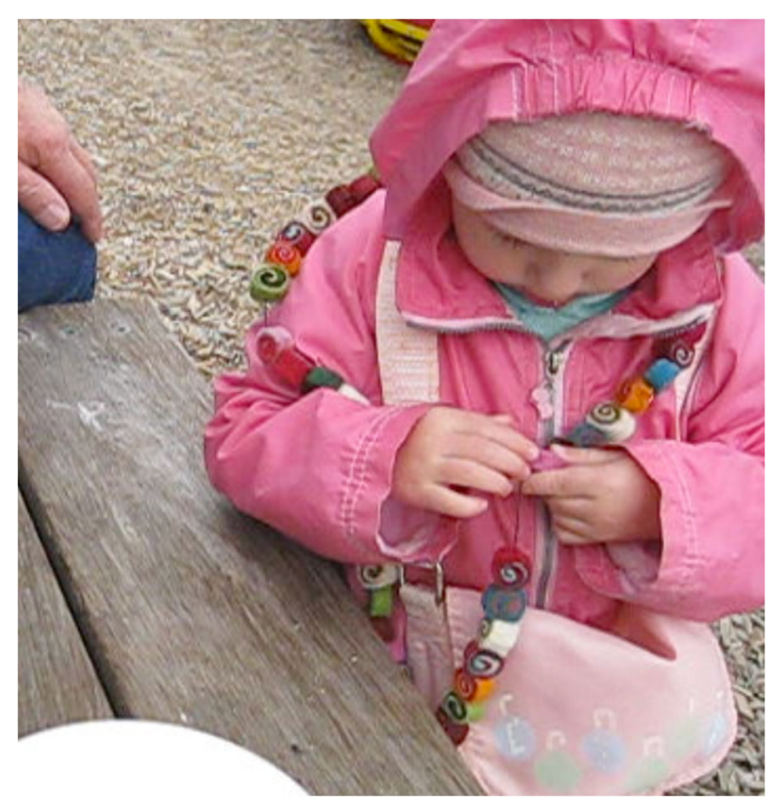

Fig. 1 Luci touches a felt bead in the necklace

stay where she moves them to, and do not slip backwards. The qualities of the beads spark an interest for toddler Luci who returns to this interest later in the day when she is walked in the stroller by her grandparents to visit her long day care.

\section{Tranformative actions in imaginative life}

Whilst being walked in a stroller through the local neighbourhood to her local long day care (LDC), Luci asks to hold her grandmother's felt bead necklace. It had been removed from around her neck when her coat was changed for LDC. In Fig. 4 image Luci has the new coat on and also wears tiger ears (she has been imagining tiger for weeks). She gently holds onto the felt necklace with both hands as the walk to LDC begins.

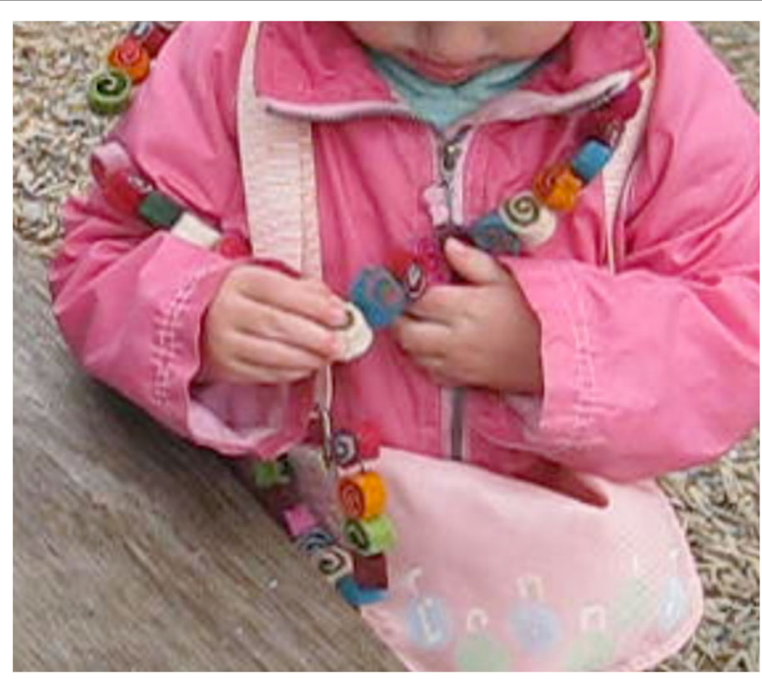

Fig. 2 Luci explores felt necklace beads 


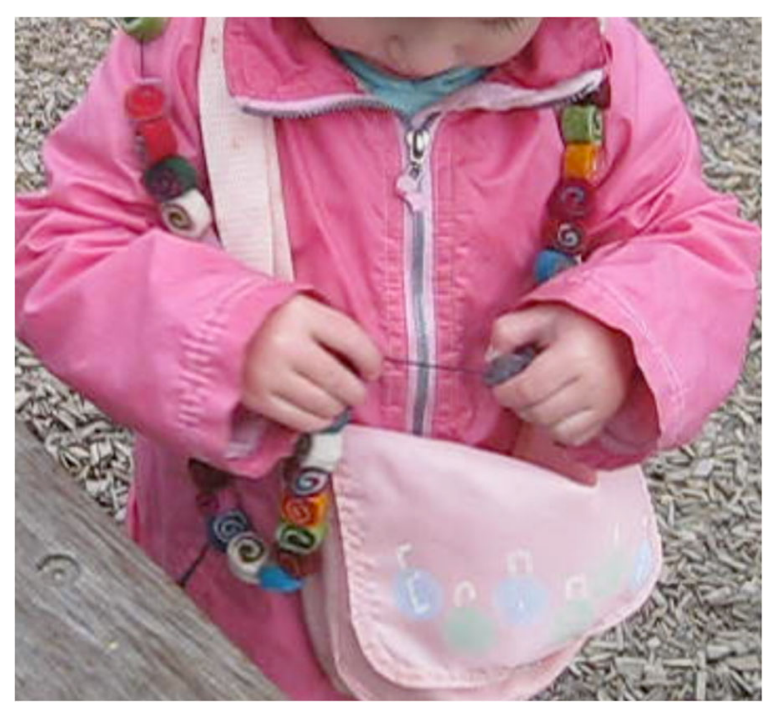

Fig. 3 Luci moves one bead along necklace string

Wearing the tiger ears is important to mention here, as it reflects Luci's ongoing imaginative life where her becoming a tiger emerged after being read a tiger story. Standing in front of her father one day, Luci began swishing her arm behind her like a tail, saying 'tiger, tiger' then to father's surprise she dropped onto hands and knees taking her toy rabbit in her mouth, pretending to be a tiger with food. Father later extended interest by buying tiger ears and tail for Luci to wear. Her tiger persona continues with regular wearing of the tiger ears. Nichols and Stich (2007) confirm the fact that young children bring action to their imaginary play: "perhaps the most obvious fact about pretense is that pretenders actually do things...they engage in actions that are appropriate to the pretense" (p.8). On the pavement walk Luci engages in new action (Fig. 5). She initiates new action by transforming the felt bead necklace into a counting tool. Her grandparents participate by being responsive, surprised and interested enough to record the action.

Luci continues to hold the necklace with both hands and begins feeling the felt beads, then starts to slide them along the string, one at a time (Fig. 5). Whilst walking along the Grandparents clearly hear Luci say the number word five. They stop pushing the stroller to look at what prompts Luci's to say five and move closer to hear her soft voice. Luci is moving the felt beads along the necklace string one by one. This appears to be the trigger for Luci to initiate an extraordinary moment and begin the symbolic activity of counting (fig. 5). The manner in which the felt beads stay in place as they are moved along the string, helps Luci as she briefly counts them using a one to one counting sequence. Grandmother uses her mobile phone to video capture Luci playfully counting the felt beads. A fifty second video results.

The transcript of this video follows.

\section{Video transcript of example}

$\underline{\text { Luci Five.... }}$

Grandparents stop pushing the stroller to listen and look. 


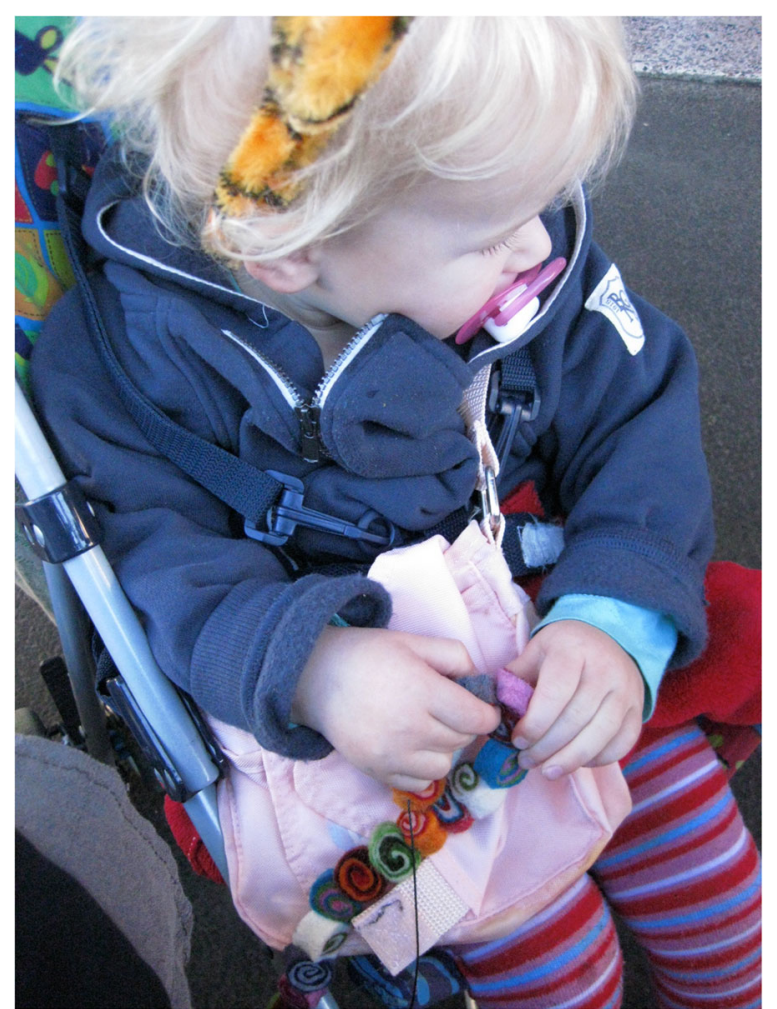

Fig. 4 In stroller holding felt necklace

Granny says to Luci, keep going.

Poppy adds: six, ....eight,

Luci starts to count the next bead and says...six, .....

Granny wants to capture the moment on video and says hold on, three, four, five,... Luci begins counting again: Two, three, four, five, six, seven, eight,

Poppy. Eight?

Luci continues counting on nine, ten......leven.

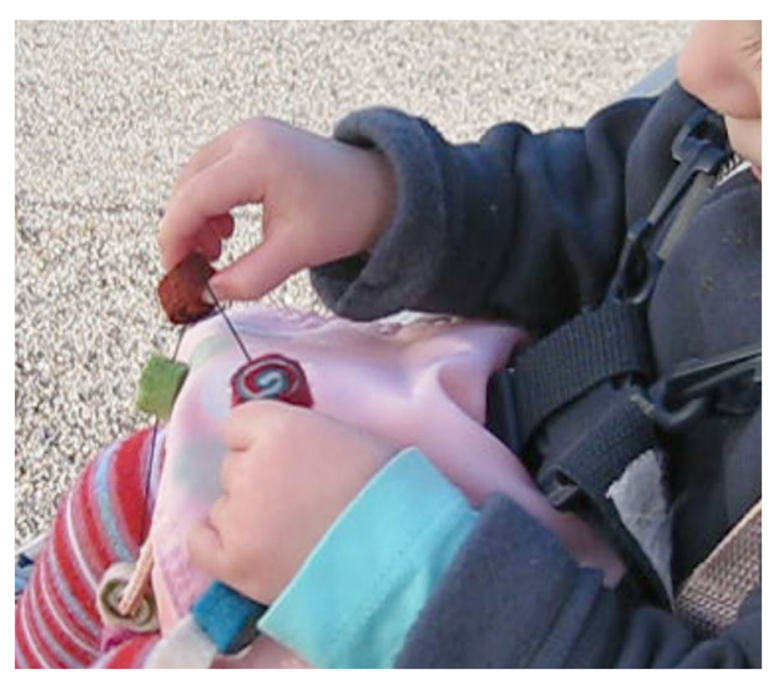

Fig. 5 Moving felt beads along string and counting one at a time 
Luci stops.

Poppy encourages: twelve, thirteen,

Luci has stopped counting.

Granny encourages Luci to start again: one two three four,

Luci has finished.

Poppy finalises with very good and starts pushing the stroller again.

The fortuitous capturing of data on the mobile phone to share with family was a moment of excitement for all family including Luci. It was also a moment of research opportunity.

\section{Discussion}

The transitory moment video that captured Luci counting felt necklace beads, is an example of how and why researchers and educators should to pay attention to the smallest moments in a toddler's daily life. In capturing these moments, it becomes possible to gain pedagogical insight into a toddlers' symbolic activity, and more importantly, to extend possibilities for supporting their learning.

Toddler Luci is active, imaginative and curious. The video transcript example narrates fifty seconds of dynamic and creative action that would have been bypassed unseen, unless adult interest, pedagogical awareness and video technology were present. It is an example of toddler-initiated play that shows how symbolic activity begins.

\section{Re-assigning meaning}

Luci's first moment of applying the symbolic activity of counting and creatively reassigning meaning to a new material artefact, (the felt bead necklace), was received in amazement and surpise by her grandparents. Already the subject of deep interest, the fifty second video capture of Luci's momentary interaction, opened up opportunities to share and celebrate Luci's growing skills and understanding of the world around her. Moyles et al. (2002) for example, support the idea that "Play and playful forms of activity potentially lead towards increasingly mature forms of knowledge, skills and understanding (p.21)." In the mobile phone video data there is evidence that Luci's playful forms of activity with the felt bead necklace, led her towards imaginative expression of symbolic knowledge. It also showed her agentic imagination in the way her playful activity was unified and embodied in layered influences of emotion, cognition and the surrounding environment (Ridgway et al. 2016). The transcript reveals that a simple walk in the stroller with Luci became an impressionable and affective activity for all participants. Having grandparent's supportive attention, provided Luci with established, familiar, responsive and reciprocal relations. Grandparents know and love Luci. They had thought that the qualities of granny's necklace would be alive with imaginative and creative possibilities for Luci's already established interest in combinations of colour and pattern. Luci's attention to details of colour and pattern are continually educated at home in her mother's art studio and embodied in Luci's playful thoughts, actions and expressive, colourful creations. "A child's play is not simply a reproduction of what he has experienced, but a creative re-working of the impressions he has acquired" (Vygotsky 2004, p.5). The surprising creative re-working, occurs in Luci's action of using the felt bead necklace like a counting frame or abacus. From Bruner (1973 p.209) comes the idea that "an act that produces effective surprise - this I shall take as the 
hallmark of a creative enterprise." Luci's capacity to initiate counting in a one to one sequence surprised her grandparents, and could certainly be considered an act of creative enterprise.

In a "Key To Learning" (KTL) Russian program for children aged 3 to 7 reported by Guitard et al. (2011) there is a curricular unit called "Sensory Mathematics". This is of interest in relation to the counting example in this article, as the Russian program aims to develop a young child's ability to analyze the visual and external qualities of the objects using sensory standards such as the color, shape and size. The importance of this program appears to be that it recognises the acquisition of sensory mathematics in human culture. This acquisiton not only depends on specific knowledge, skills and adult guidance, but also on the child's use of sensory signs and symbols. Luci, aged 23 months, is drawn to sensory acquisition of these mathematical sensibilities through her family culture. She is able to demonstrate them in the example of her active exploration and imaginative play with a cultural object, the felt bead necklace.

\section{Drawing on accumulated experience}

The following narrative is included in this article as it links the video data example to family activity in order to clarify the cultural milieu of Luci's family. Prior to capturing the mobile phone video data, a family gathering around a dinner table makes a connection between Luci's counting experience (Wagoner 2017) and her transitory symbolic play moment with the felt necklace. The context for the connection is the family home where Luci is sitting on her aunt's knee around a dinner table. Aunt begins a guessing game by taking a sugar snap pea from a bowl and asking how many peas in the pod? Aunt playfully holds the pea pod up to her own face to pretend it's an upwardly curving smile. Luci smiles and watches her Aunt intently. Luci has been opening the pea pods herself and feeding on the peas inside, not thinking about how many peas are in each pod. Luci looks at Aunt's pea pod and answers 'two' and when the pod is opened she sees that there are indeed two peas in the pod. Luci's face lights up with a huge smile and with a glancing gesture to her family around the dinner table she sees their nods and looks of beaming recognition, as they acknowledge she correctly guessed the number of peas. Luci has an understanding of what 'two' can be; in this case, two peas in a pod. In the light of this small story, the notion that Vygotsky (2004, 7-97) considered creative activity is based on the ability of the brain to combine elements, fits very well: "whenever a person imagines, combines, alters, and creates something new, no matter how small, this thing appears ...compared to the work of others." Luci has configured a new thing (two-ness) in her home situation. Davydov (2008) had observed that: "A person's conscious activity is mediated by the collective" (p. 31). Past collective mediations such as those learned around the dinner table, are implicitly present in collective memory. In this way when Luci brings past collectively mediated experiences to her present handling of the felt beads, she already remembers and understands that counting is useful and valued in her family life (White and Dalli 2017). Vygotsky (1994) notes in relation to cultural development of the child: "the amount remembered is determined by the degree of his [her] attention, by the amount of his individual memory and by the measure of his interest in the matter" (p.64). 


\section{Caring attentive interactive relationships}

The social and emotional support of interested, playful and attentive family members sitting around a dinner table, do reflect a place where "human connection and caring support" exist for Luci (Mahn and Steiner p. 50). Stetsenko (2008) adds that over time, it is our social practices that form us, form the world, and that humans do not adapt but are continuously active in creating culture through interaction with their world around them.

Arievitch and Stetsenko (2014, p.217) suggested that "The transformational power of sign mediation" was insufficiently explained in Vygotsky's attempts to close the gap that he saw between "external activities and the human mind." In Luci's unexpected symbolic action of using the felt beads to mediate an early counting activity, she demonstrates how the external object and internal thinking have transformational power when supportive conditions for learning exist.

\section{Findings}

From the above discussion around the example, it is found that mobile phone video is an appropriate research tool for capturing fleeting spontaneous moments of learning in toddler initiated play. Any limitations that a larger video camera may bring (including its size and more obvious presence) are over come when the mobile phone is used to capture a transitory moment without intrusion. The family researcher records spontaneously on the mobile phone as the moment unfolds. The recording of spontaneous moments of toddler play by family is considered ethical. Permission is given by proxy to capture Luci's everyday moments in this situation and the challenge lies with the capacity of the researcher to incorporate roles of family member and researcher and do no harm to Luci. As mentioned earlier, the family regulary record unfolding moments in Luci's daily life and gave written permission for Luci's participation in the research. At the time this video was taken on a mobile phone, Luci was undisturbed by family members regularly recording her activity at home, in her community and LDC centre. The intentions in all places were to honour her lively activity and share it back with her. The data show Luci as a confident toddler with a capacity to think for herself, initiate ideas and connect her lived experiences in meaningful and expressive ways.

Mahn and John-Steiner (2002) write about confidence being a gift gained through caring support rather than punitive support. Luci's life is found to involve affective and creative relationships where her interests are supported, encouraged and extended.

Luci's toddler-initiated learning is an act of confidence and creative expression.

It is also found that in a playful family life that takes creative approaches to materials in daily activity, toddler Luci's imagination is encouraged and used. Learning to count for example, is collectively distributed across the actions of individuals, families and the cultural tools available to Luci.

\section{Conclusion}

The use of mobile phone video helps to capture the immediacy of a transitory moment but at the same time requires the researcher to be aware of the toddler and open to filming spontaneous toddler initiated action. 
Luci experiences perezhivane in her play activity moments and social relations, where there occurs an active individual refraction of the changes she has lived through in her particular environment (Veresov 2016; Veresov and Fleer 2016). These refracted experiences combine in the social situation of Luci's video captured moment of play and give birth to her self initiated performance. The recognition of her self initiated symbolic activity of counting in a one to one sequence was an unexpected surprise for the researcher. When re-considered and viewed in a holistic way within family and community life, toddler Luci's experiences make clearer that what is valued and noticed by adults, exerts influence on a toddler's learning and development. Realising that mobile phone video data offer research insight into how a toddler can, in a passing moment, imbue a cultural object with new symbolic meaning, should encourage researchers to capture these moments, and thereby elevate the art and science of visual methodology in early childhood research.

\section{Publisher's Note}

Springer Nature remains neutral with regard to jurisdictional claims in published maps and institutional affiliations.

Received: 21 August 2017 Accepted: 20 December 2017

Published online: 05 January 2018

\section{References}

Arievitch I, Stetsenko A (2014) The "magic of signs" developmental trajectory of cultural mediation. In: Yasnitsky A, van der Veer R, Ferrari M (eds) The Cambridge handbook of cultural-historical psychology. Cambridge University Press, pp 217-244

Bozhovich L (2009) The social situation of child development. J Russ East Eur Psychol 47(4):59-86

Bruner JS (1973) The conditions of creativity. In: Beyond the information given: Studies in the psychology of knowing, vol 12. W.W. Norton, New York, pp 208-217

Davydov W (2008) Problems of developmental instruction. A theoretical and experimental psychological study. In: Robbins D, Lektorsky V (eds) International perspectives on Non-Classical Psychology Series. Nova Science Publishers, New York

Elkonin DB (1978) Psychologija igry [the psychology of play]. Pedagogika, Moscow

Fleer M (2010) Early Learning and Development: cultural-historical concepts in play. Cambridge University Press, Australia

Fleer M (2014) Theorising play in the early years. Cambridge University Press, New York

Fleer M, Hedegaard M (2010) Children's Development as Participation in Everyday Practices across Different Institutions. Mind Cult Act 17(2):149-168

Fleer M, Ridgway A. (eds) (2014) Visual methodologies and digital tools for researching with young children: transforming Visuality, International perspectives on early childhood education and development, vol 10. Springer, Dordrecht

Gonzalez-Rey FL (2009) Historical relevance of Vygotsky's work: its significance for a new approach to the probem of subjectivity in psychology. Outlines Crit Pract Stud 11(1):59-73 ISSN 1904-0210

Guitard, M.E., Sidera, F., Doylas, G. \& Veraksa, N. (2011). "Key to learning". A neo-Vygotskian program for children aged 3 to 7. Revista de Psicología y Educación Núm. 6, pág. 69-78 ISSN:1699-9517.e-ISSN:1989-9874.

Hedegaard, M. (2008). A cultural-historical theory of children's development. In, Hedegaard, M., Fleer, M. with Bang, J. and Hviid, P. Studying Children A Cultural-Historical Approach.. U.K.: Mc Graw Hill Open University Press. (2) 10-29

Kravtsov GG, Kravtsova EE (2010) Play in L. S Vygotsky's nonclassical psychology. J Russ Easter Eur Psychol 48(4):25-41

Li, L., Quinones G.G., Ridgway, A. (Eds.) (2017) Studying babies and toddlers: Relationships in cultural contexts. (1st) (International perspectives on early childhood education and development; no. 20). Singapore: Springer (175-192). DOI: https://doi.org/10.1007/978-981-10-3197-7

Mahn H, John-Steiner V (2002) The gift of confidence: a Vygotskian view of emotions, Learning for Life in the $21^{\text {st }} \mathrm{C}$ Socio cultural perspectives on the future of education, pp 46-58

Moyles, J., Adams, S. \& Musgrove, A. (2002). Brief no: RB363, study of pedagogical effectiveness in early Learning. Anglia Polytechnic University

Nichols S, Stich S (2007) A cognitive theory of pretense. Rutgers University Research Group on Evolution and Higher Cognition, USA, pp 1-32

Quiñones G, Fleer M (2011) "visual Vivencias": a cultural-historical tool for understanding the lived experiences of young children's everyday lives. In: Johansson E, White J (eds) Educational research with our youngest: Voices of infants and toddlers. Springer, Netherlands, pp 107-129

Quinones G, Li L, Ridgway A (2017) Transitory moments as "affective moments of action" in toddler play. In: Li L, Quinones GG, Ridgway A (eds) Studying babies and toddlers: Relationships in cultural contexts, vol 12, 1st edn. Springer (International perspectives on early childhood education and development; no. 20), Singapore, pp 175-192. https://doi.org/10.1007/978-981-10-3197-7 
Ridgway A, Li L, Quinones G (2016) Transitory moments in infant/toddler play: agentic imagination. Int Res Early Childhood Educ 7(2):91-110

Ridgway A, Quinones GG, Li L (2015) Early childhood pedagogical play: a cultural-historical interpretation using visual methodology, 1st edn. Springer Verlag, Singapore. https://doi.org/10.1007/978-981-287-475-7

Stetsenko, A. (2008). Conceptions and research from cultural-historical approaches on motive and values in children's development, as well as how to confront the ethical aspect of this problem area in practice. ISCAR PRE-CONFERENCE WORKSHOP ON CHACDOC (Cultural-historical approaches to children's development and childhood) section meeting (www.iscar.org/section/chacdoc University of san Diego September $8^{\text {th }} 2008$

Trevarthen C (2017) Prologue: under-three year olds in policy and practice (vi). In: Policy and Pedagogy with Underthree Year Olds: Cross - disciplinary Insights and Innovations. Springer Nature, Singapore

Vadeboncoeur J, Kady-Rachid H, Moghtader B (2014) Learning in and across contexts: reimagining education. In: Yearbook of the National Society for the Study of Education, 113th, pt. 2 http://www.researchgate.net/publication/ 274834602

van Oers B (2010) In: Brooker L, Edwards S (eds) Children's enculturation through play, Engaging play. McGraw-hill, UK, pp 195-209

Veresov N (2016) Perezhivanie as a phenomenon and a concept: questions on clarification and methodological meditations. Cult Hist Psychol 12(3):129-148. https://doi.org/10.17759/chp.2016120308 http://psyjournals.ru/en/kip/ 2016/n3/veresov.shtml

Veresov N, Fleer M (2016) The journey forward. Mind Cult Act 23(4):350-352 http://www.tandfonline.com/doi/full/10. 1080/10749039.2016.1199704

Vygotsky LS (1987) Imagination and its development in childhood. In: Reiber RW, Carton AS (eds) The collected works of L.S. Vygotsky. Plenum Press, New York, pp 339-350

Vygotsky LS (1994) The problem of the cultural development of the child. In: Van der Veer R, Valsiner J (eds) The Vygotsky reader (5) 57-72. Cambridge USA Blackwell Publishers, Oxford

Vygotsky LS (1997) Research method. In: Rieber RW (ed) The Collected Works of L.S. Vygotsky, Volume 4 The History of the Development of Higher Mental Functions, vol 2, New York, Plenum Press, pp 27-63

Vygotsky LS (2004) Imagination and creativity in early childhood. J Russ East Europ Psychol 42(1):7-97

Wagoner B (2017) The physiognomics of creativity. In: Cresswell et al (eds) Dialogue and Debate in the making of Theoretical Psychology, vol 2. Captus Press, Toronto, pp 25-30

White EJ, Dalli C (eds) (2017) Under-three year olds in policy and practice, Policy and Pedagogy with Under-three Year Olds: Cross -disciplinary Insights and Innovations. Springer Nature, Singapore

Submit your manuscript to a SpringerOpen ${ }^{\circ}$ journal and benefit from:

- Convenient online submission

- Rigorous peer review

- Open access: articles freely available online

- High visibility within the field

- Retaining the copyright to your article

Submit your next manuscript at $\gg$ springeropen.com 